Check for updates

Cite this: RSC Adv., 2017, 7, 42845

Received 31st May 2017

Accepted 24th August 2017

DOI: 10.1039/c7ra06075k

rsc.li/rsc-advances

\title{
Facile fabrication of lipase to amine functionalized gold nanoparticles to enhance stability and activity $\dagger$
}

\author{
Sristy Shikha, (D) ${ }^{a}$ Krishan Gopal Thakur (D) $^{b}$ and Mani Shankar Bhattacharyya (DD *a
}

Among various techniques of immobilization, EDC/NHS cross linking is a simple and single step process for covalent coupling between enzymes and nanoparticles. Here we describe immobilization of lipase on amine functionalized gold nanoparticles $\left(A u N P s-N_{2}\right)$ to attain enhanced activity and stability. To achieve a suitable orientation, it is necessary to understand the contribution of different functional groups on the enzyme's surface. Therefore, the crystal structure of lipase was analyzed using a computational method (PyMOL) to find the exposed acidic amino acid residues that can be exploited for conjugation. Confirmation of conjugation (AuNP-NH- -lipase) was determined by various techniques such as agarose gel electrophoresis, zeta measurement, FTIR-spectroscopy and TEM. Further, catalytic parameters $\left(V_{\text {max }}, K_{\mathrm{M} \text {,app }}, K_{\mathrm{cat}}\right.$, and $\left.K_{\mathrm{cat}} / K_{\mathrm{M}, \text { app }}\right)$ have been studied to establish activity enhancement upon immobilization. The data also suggested that, AuNP- $\mathrm{NH}_{2}$-lipase has desirable improved parameters such as temperature and storage stability. The thermodynamic parameters for the kinetics of deactivation $\left(\Delta H_{\mathrm{D}}^{\circ}, \Delta S_{\mathrm{D}}^{\circ}\right.$ and $\left.\Delta G_{\mathrm{D}}^{\circ}\right)$ of the AuNP-NH $\mathrm{N}_{2}$-lipase and free lipase demonstrated better stability of the conjugate. $\mathrm{CD}$ and fluorescence spectroscopic studies revealed minor structural rearrangements in the enzyme upon conjugation. Thus the AuNP- $\mathrm{NH}_{2}$-lipase conjugate represents a novel enzyme preparation with attributes of high activity and stability that could be an attractive choice in diverse applications ranging from catalysis to diagnostics.

\section{Introduction}

Enzymes have wide application in food, detergent, medicine, diagnostics, energy and many other industrial sectors due to their catalytic activity under mild conditions, specificity, costeffectiveness and greener production conditions. ${ }^{1,2}$ However industrial application of free enzymes is restricted due to high lability, poor stability and problems in their recovery and reuse. ${ }^{3}$ Immobilization is the effective way to overcome these limitations and extend the horizon of their applications. ${ }^{4}$ Various methods of immobilization include physical adsorption, ionic interaction, covalent bonding between support and enzyme or entrapment within the different matrices. ${ }^{5}$ Hydrophobic interactions, ionic interactions, hydrogen bonds, van der Waals interactions and solvation are the major forces responsible for non-covalent interactions. Except for covalent attachment, the above mentioned techniques mainly rely on weak interactions,

${ }^{a}$ Fermentation Science and Biocatalysis Laboratory, CSIR-Institute of Microbial Technology, Sector 39 A, Chandigarh-160036, India. E-mail: manisb@imtech.res.in; Fax: +91 1722695215; Tel: +91 1726665313

${ }^{b}$ Structural Biology Laboratory, G. N. Ramachandran Protein Centre, CSIR-Institute of Microbial Technology, Chandigarh 160036, India

$\dagger$ Electronic supplementary information (ESI) available: The pH and storage stability data. See DOI: 10.1039/c7ra06075k therefore enzymes are prone to detachment from the support surface with time. Covalent bonding mediated immobilization helps in improving enzyme activity at the cost of loss of conformational integrity. ${ }^{6}$ A very simple method of crosslinking biomolecules to nanoparticles relies on EDC/NHS coupling in which carbodiimides mediate formation of amide bond between carboxy and amine groups. ${ }^{7}$ High solubility in water, ease to remove byproducts, zero length cross linking molecule and single step reaction provides an edge over other methods in EDC/NHS coupling. ${ }^{8}$ Several enzymes have been conjugated using this strategy, but they lack in their structure based consideration prior to immobilization. Improper orientation after immobilization ultimately affects activity; therefore, it is highly essential to understand the structure of protein before immobilization. One of the rationale approaches is to exploit specific surface amino acids for conjugating enzymes with the nanosurface so that the catalytic properties of the enzyme do not alter significantly, but the structural integrity and stability of the enzyme improves.

Nanoparticles (NPs) have emerged as the choice for matrix to immobilize enzyme due to many positive attributes such as, high dispersity and surface area, biocompatibility and availability of tools to manipulate the surface. ${ }^{9}$ Moreover, size, surface functional group available for conjugation, structure and textural attributes of the NPs has profound effect of the tethered 
enzyme. ${ }^{10}$ Among numerous metal nanoparticles, the property of bio-conjugation, size dependent optical and electrical properties and good biocompatibility have made gold nanoparticles a potential candidate for diverse application such as biosensor, drug delivery system, bioimaging, and cancer therapy. ${ }^{\mathbf{1 1 - 1 3}}$

Lipases (triacylglycerol hydrolases, EC 3.1.1.3) are found ubiquitously from prokaryotes like bacteria to eukaryotes (yeasts, plant and animals) that catalyzes diverse reactions such as hydrolysis, and the synthesis of esters formed from glycerol and long-chain fatty acids. ${ }^{\mathbf{1 4}}$ It has potential industrial applications in food, detergent, cosmetics, pharmaceutical, paper and pulp industries and biotechnological application like biodiesel production and bioremediation..$^{15,16}$ Understanding its extensive applications, attempts have been made to conjugate the enzyme to improve stability and reusability of the biocatalyst. To attain this goal different techniques of immobilization have been applied using various matrices like gelatin, chitosan, mesoporous silica, magnetite nanoparticles etc. ${ }^{17-19}$ However, during conjugation aggregation of nanoparticles pose major hurdle as it reduces available surface area for enzyme immobilization or reduces availability of the substrate to the enzyme during catalysis. On the other hand, surface coupling of the enzyme to the NPs, may block the substrate binding site, or may interfere with the necessary conformational changes required for enzyme activity. ${ }^{20}$ Therefore, to address these issues; uniform distribution and proper orientation of enzyme upon immobilization with fully retained activity, we have designed our study by choosing amine functionalized gold nanoparticles as matrix and EDC/NHS as coupling agent.

In the present study, we have used rational structure based, directed immobilization approach to generate highly active and stable nanozyme conjugate. Here we have synthesized amine functionalized gold nanoparticles (AuNPs-NH $\left.\mathrm{N}_{2}\right)$ to target surface carboxyl group (aspartic and glutamic acids) of lipase. To understand the contribution of acidic amino acid residues towards immobilization as well as structural and functional aspect, crystal structure of lipase (3-LIP) from Burkholderia cepacia, was analysed using PyMOL software. These acidic amino acids present at the surface of the lipase were identified and explored for conjugation with AuNPs-NH $\mathrm{N}_{2}$ using EDC/NHS chemistry. Further, different concentrations of lipase were used to obtain maximum immobilization without aggregation. These AuNP- $\mathrm{NH}_{2}$-lipase composites have been characterized by UVvisible spectroscopy, FTIR and TEM imaging. Further, the kinetic analysis of the catalytic activity, stability parameters and thermodynamic parameters for the deactivation of the free and conjugated enzyme has been determined. CD and fluorescence spectroscopic studies were also carried out to understand the structural changes in the enzyme as an outcome of conjugation. This water-soluble, highly active and stable AuNPs- $\mathrm{NH}_{2}$-lipase nanozyme conjugate may be useful for various applications.

\section{Methods}

\section{Material}

Gold(III) chloride hydrate (50\% Au basis), cysteamine-HCl, NHS were purchased from Sigma-Aldrich and $\mathrm{NaBH}_{4}$ was purchased from Merck. Lipase PS Amano (from B. cepacia), 4-nitrophenyl palmitate, Bradford reagent, EDC and NHS were procured from Sigma-Aldrich. para-Nitrophenol was purchased from Himedia, India. All chemicals and buffer components used in this study were of highest purity grade available.

\section{Structural studies}

Structural analysis of $B$. cepacia lipase (3LIP) was carried out using PyMOL software. The number and disposition of the acidic amino acids were analyzed and finally, the surface exposed acidic amino acid residues have been explored to conjugate the enzyme with the amine functionalized gold nanoparticles.

\section{Synthesis and characterization of gold nanoparticles}

Amine functionalized gold nanoparticles were synthesized following the method reported by Lee et al., with slight modification. ${ }^{21}$ Briefly, for $10 \mathrm{ml}$ of $\mathrm{HAuCl}_{4}$ solution (40 ppm, pH 5.5), $100 \mu \mathrm{l}$ of $0.213 \mathrm{M}$ cysteamine- $\mathrm{HCl}$ solution in water was added and the mixture was stirred for $20 \mathrm{~min}$ at room temperature (RT) in the dark. Freshly prepared $\mathrm{NaBH}_{4}$ solution $(1.25 \mu \mathrm{l}$, $10 \mathrm{mM}$ ) was further added to it and reaction mixture was again stirred at RT in the dark until the appearance of red wine colored solution. AuNPs- $\mathrm{NH}_{2}$ solution was dialysed against MQ to remove the traces of unreacted gold ions and $\mathrm{NaBH}_{4}$ and stored at $4{ }^{\circ} \mathrm{C}$ for further use.

\section{Conjugation of lipase with AuNPs- $\mathrm{NH}_{2}$, protein content measurement and immobilization efficiency}

Conjugation of the lipase to AuNPs- $\mathrm{NH}_{2}$ was done by employing 1-ethyl-3-(3-dimethylaminopropyl)carbodiimide (EDC) and $\mathrm{N}$-hydroxysuccinimide (NHS) chemistry. ${ }^{22}$ In this method, the carboxyl group of enzyme (lipase) was activated by EDC and the intermediate was stabilized by NHS that subsequently reacted with the amino groups of the gold nanoparticles and form amide bond.

In brief, $1.91 \mathrm{mg}$ of EDC and $2.88 \mathrm{mg}$ of NHS was added to $1 \mathrm{ml}$ of $50 \mathrm{mM}$ MES buffer solution containing four different concentrations of lipase, and the solution was stirred (150 rpm) for $15 \mathrm{~min}$ at RT for activation of carboxy group of Asp and Glu of enzyme. This mixture was transferred to $9 \mathrm{ml}$ of amine functionalized gold nanoparticles solution and further incubated on stirring for next 2-3 hours. After completion of the reaction, the solution was dialyzed against $\mathrm{MQ}$ water to remove intermediate products, excess EDC and NHS. Conjugated AuNPs- $\mathrm{NH}_{2}$-lipase solution was kept at $4{ }^{\circ} \mathrm{C}$ for further use.

The protein content of the lipase was determined by colorimetric assay i.e., Bradford's method $^{23}$ using bovine serum albumin (BSA) as standard. For estimation of actual protein content of lipase powder (lipase from PS Amano B. cepacia, Sigma), $1 \mathrm{mg} \mathrm{ml}^{-1}$ solution was prepared in phosphate buffer ( $\mathrm{pH}$ 7.2), centrifuged to remove insoluble parts and then Bradford assay was performed. $1 \mathrm{mg}$ of lipase powder correspond to $5.2 \mu \mathrm{g}$ of protein content. Thereafter, all the concentration of lipase mentioned here are in terms of actual protein content. The efficiency of immobilization was expressed as \% of immobilization as shown in given formula. 


$$
\% \text { immobilization }=(A-B) \times 100 / A
$$

where: $A=$ total protein used for conjugation, $B=$ protein content in supernatant of AuNPs- $\mathrm{NH}_{2}$-lipase solution.

In order to avoid the interferences of nanoparticles, the $\mathrm{OD}_{590}$ of AuNPs- $\mathrm{NH}_{2}$ supernatant was also deducted from the $\mathrm{OD}_{590}$ of the supernatant of AuNPs-NH $\mathrm{N}_{2}$-lipase.

\section{Characterizations of lipase conjugated AuNPs- $\mathrm{NH}_{2}$}

Conjugation of lipase with AuNPs- $\mathrm{NH}_{2}$ was monitored by UVvisible spectrophotoscopy using Hitachi dual-beam spectrophotometer (Hitachi U-2900) operated at a resolution of $1 \mathrm{~nm}$. The spectral measurement was taken in the range of $400-$ $700 \mathrm{~nm}$. Further, size measurement and the residual surface charge were measured by Malvern zetasizer. The zeta potential (५) was determined by laser doppler electrophoresis (LDE) using a quartz capillary electrophoresis cell. All of the measurements were performed in triplicate for a single batch of NPs, and the results shown are the average of these measurements. Confirmation of conjugation was also done by agarose gel electrophoresis $(0.8 \%)$.

\section{Fourier transform infrared (FTIR) spectroscopy}

FTIR spectroscopy was used to understand the conjugation lipase with AuNPs- $\mathrm{NH}_{2}$. The sample was prepared in $\mathrm{KBr}$ pellet. FTIR spectra of the films were recorded on instrument Vertex 70 operated in the diffuse reflectance mode at a resolution of $4 \mathrm{~cm}^{-1}$. To obtain good signal to noise ratio, 256 scans of the bio-conjugate film were taken in the range $400-4000 \mathrm{~cm}^{-1}$ and spectra was compared with free enzyme and gold nanoparticles.

\section{Transmission electron microscopy measurements}

TEM measurements were performed on a JEOL Model 2100 instrument operated at an accelerating voltage of $120 \mathrm{kV}$. TEM samples were prepared by placing a drop of centrifuged and resuspended AuNPs- $\mathrm{NH}_{2}$ and AuNP- $\mathrm{NH}_{2}$-lipase on carboncoated TEM copper grid. The film was allowed to dry for $10 \mathrm{~min}$ and the extra solution was removed using a blotting paper. Negative staining using $2 \%$ phosphotungstic acid (PTA) was done to visualize protein immobilized on the AuNPs- $\mathrm{NH}_{2}$ surface.

\section{Enzyme activity assay}

The catalytic activity of lipase was examined by measuring the release of $p$-nitrophenol ( $p$-NP) from substrate $p$-nitrophenyl palmitate ( $p$-NPP) at $410 \mathrm{~nm}$ as described by Kuo et al., and Gupta $e t$ al., with some modifications. ${ }^{24,25}$ In brief, stock of $p$-NPP $(25 \mathrm{mM})$ was prepared in ethanol, from which different concentration range (0-25 mM) was made. Free and immobilized enzyme solution $(10 \mathrm{nM})$ was prepared in $10 \mathrm{mM}$ phosphate buffer (PB, pH 7.2). $100 \mu \mathrm{l}$ of each dilution of substrate was mixed with $100 \mu \mathrm{l}$ of enzyme solution as mentioned and incubated at $37^{\circ} \mathrm{C}$ for $5 \mathrm{~min}$ and then, $200 \mu \mathrm{l}$ of $0.5 \mathrm{~N} \mathrm{Na}_{2} \mathrm{CO}_{3}$ containing Triton-X100 was added to terminate the reaction. Finally, the release of $p$-nitrophenol ( $p$-NP) resulting from the lipase catalyzed hydrolysis of $p$-NPP was measured at $410 \mathrm{~nm}$ with required dilution. In order to avoid the interferences of nanoparticles, similar reaction mixture for all concentrations of nanoparticles (that have been used during experiments but without substrate) was prepared, following same experimental procedure and $\mathrm{OD}_{410}$ was measured. Later this value was deducted from the experimental samples and then calculation were performed. Inferences of substrate solution were also considered and deduced from measurement. For calculation of apparent Michaelis-Menten constant $\left(K_{\mathrm{M}, \mathrm{app}}\right)$ and $V_{\max }$, the experiment was done in triplicate, average of these was plotted and data was analyzed through Prism software. One unit of enzyme activity was defined amount of enzyme required to produce $\mu \mathrm{mol}$ of product released per minute under experimental condition.

\section{Determination of the immobilized lipase stability}

Thermal stability. The stability of the lipase (free and immobilized) was evaluated by measuring the enzyme activity before and after treatment and represented as relative activity. Thermal stability (for thermodynamic characterization of the enzyme) was evaluated by incubating the enzyme for stipulated time at temperatures ranging from $30-80{ }^{\circ} \mathrm{C}$, samples were withdrawn at an interval of one hour and the activity of the enzyme was measured. All the experiment were performed in triplicate and average of these values was used for plotting graph.

pH and storage stability. The pH stability of the lipase was investigated by incubating the enzyme in buffers of different $\mathrm{pH}$ ranging from $4-10$ for one hour. Storage stability was investigated by storing the enzyme at $4{ }^{\circ} \mathrm{C}$ for a fixed time period and then, at particular interval samples were taken for activity measurement. The experiments were performed in triplicate and average of these value was used for plotting graph. To check the stability of AuNPs- $\mathrm{NH}_{2}$ before and after the conjugation, samples were taken at an interval of 5 days and measurement was performed using UV-visible spectroscopy. Lipase conjugated at $1 \mu \mathrm{mol} \mathrm{ml} l^{-1}$ concentration has been used for this assay in case of conjugated nanoparticles.

Circular dichroism (CD) spectroscopy. The secondary structure of native and conjugated enzyme was monitored by circular dichroism (CD) spectroscopy. The far-UV CD spectra (200-250 nm) was recorded on a JASCO-J-815 spectropolarimeter with a $1 \mathrm{~cm}$ pathlength cuvette with scan rate $10 \mathrm{~nm} \mathrm{~min}{ }^{-1}$ and averaged over three scans. The raw $\mathrm{CD}$ data were converted into mean residue ellipticity $\left(\Phi_{\mathrm{MRE}}\right)$, expressed as degrees square centimeter per decimole as follows:

$$
\left(\Phi_{\mathrm{MRE}}\right)=\left(100 \times \Phi_{\mathrm{obs}}\right) /[d \times C \times(n-1)]
$$

where; $\Phi_{\mathrm{obs}}=$ observed ellipticity (in degrees), $d=$ path length (in centimeters), $C=$ protein concentration (molar), and $n=$ total number of amino acids in the protein.

Fluorescence spectroscopy. The fluorescence spectra of the free and conjugated lipase were monitored using a PTIQM-40 spectrofluorimeter operating at an excitation wavelength of $280 \mathrm{~nm}$. The emission spectra were recorded from 300-400 nm 

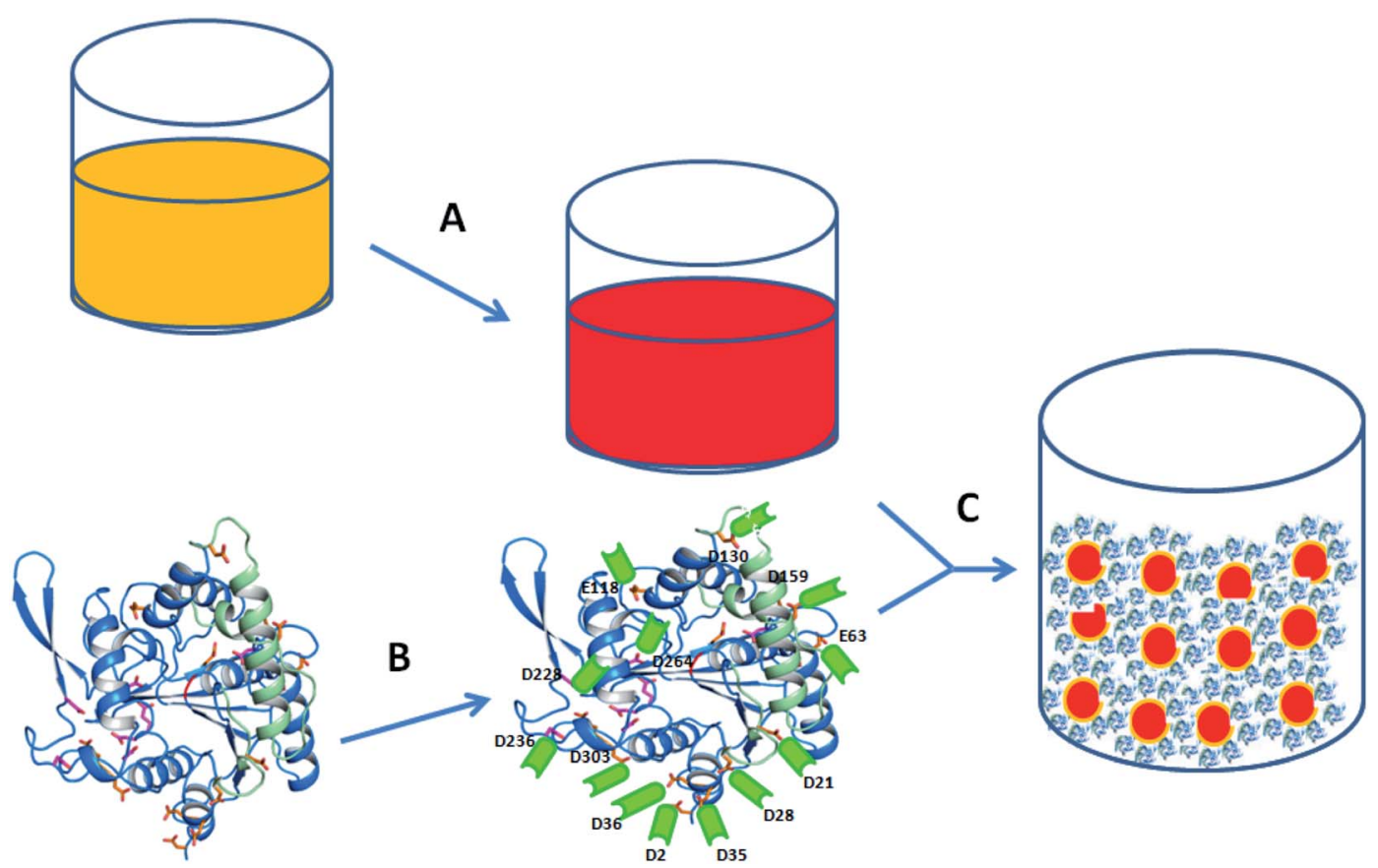

Fig. 1 Schematic illustration of formation of AuNPs- $\mathrm{NH}_{2}$-lipase nanozyme composite. Step A: Synthesis of gold nanoparticles from its salt using cysteamine- $\mathrm{HCl}$ and $\mathrm{NaBH}_{4}$; Step B: Activation of lipase using NHS \& EDC; Step C: Formation of AuNPs-NH $\mathrm{N}_{2}$-lipase nanozyme composite.

using a $5 \mathrm{~nm}$ bandwidth in both excitation and emission paths. For control studies, fluorescence spectra of AuNPs- $\mathrm{NH}_{2}$ and phosphate buffer were also recorded.

\section{Results and discussion}

\section{Structural analysis of lipase}

For this study, we have chosen lipase from B. cepacia. The enzyme is already proven to have versatile application ${ }^{\mathbf{2 6 - 2 9}}$ and its crystal structure ${ }^{30}$ has been resolved earlier. Like other lipases it poses a catalytic triad of Ser-His-Asp buried deep in to an oxyanion hole (Ser has been indicated by yellow arrow in Fig. 2A), covered by a lid and the enzyme shares same catalytic mechanism as that of other lipases. It is also suggested that, a substantial amount of reorganization of the secondary structure is required during the activity of the enzyme.

Mapping of the enzyme surface using computational methods (PyMOL) revealed the contribution of various amino acids on the structure function activity of the enzyme. The distribution of surface exposed free carboxyl group containing residues (aspartic acid, Asp and glutamic acid, Glu) has been shown in Fig. 2 along with table. The free acidic amino acid residues (categorized as accessible amino acid that does not take part in H-bond, van der Waals interactions or ionic interactions to maintain the structural integrity of the enzyme) are present on the surface on the enzyme and can be exploited for conjugation with $\mathrm{NH}_{2}$-terminated AuNPs via EDC/NHS chemistry (as shown in Fig. 1). Thus, remaining acidic amino acid residues that take part structural integrity of the enzyme through small interaction (inaccessible amino acid residues, Fig. 2) will remain undisturbed.

\section{Synthesis, conjugation and characterization of conjugated and unconjugated gold nanoparticles}

For the preparation of nanozyme composite, $\mathrm{NH}_{2}$ functionalized AuNPs were obtained from chloroauric acid solution by
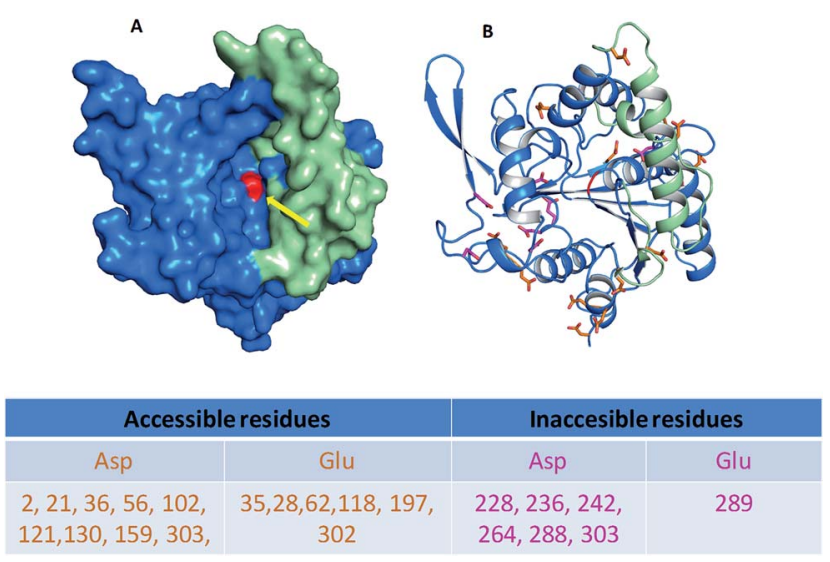

Fig. 2 The 3D structure of lipase (of 3LIP) obtained through PyMOL. Space filling model of 3LIP showing the active site residue serine (colored in red, marked with arrow), the flap of enzyme is shown in grey (A) and ribbon diagram of the same is showing the accessible and inaccessible residues (B) (orange colored amino acids indicate the accessible acidic residues (Asp and Glu), whereas the purple colored are inaccessible acidic residues). The table shows the list of inaccessible and accessible amino acid residues containing carboxyl group (Asp and Glu) of 3LIP. 


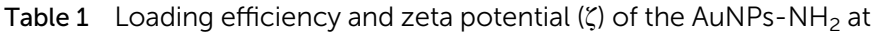
various concentration of lipase

\begin{tabular}{lll}
\hline $\begin{array}{l}\text { Concentration of lipase used } \\
\text { for conjugation }\left(\mu \mathrm{mol} \mathrm{ml} \mathrm{m}^{-1}\right)\end{array}$ & $\begin{array}{l}\text { \% immobilization } \\
\text { efficiency }\end{array}$ & $\begin{array}{l}\text { Zeta potential } \\
(\zeta)\end{array}$ \\
\hline 0 & No & 35 \\
0.5 & $85 \pm 5$ & 14 \\
1 & $92 \pm 4$ & 10 \\
2 & $25 \pm 2$ & 4 \\
4 & $15 \pm 3$ & 0.37
\end{tabular}

using $\mathrm{NaBH}_{4}$ as reducing agent and cysteamine- $\mathrm{HCl}$ as the capping agent. On the other side, the free carboxylate groups present on the surface of the lipase were activated by the watersoluble carbodiimide EDC in presence of NHS to provide stability to intermediate product. Thus, obtained NHSterminated activated lipase was further mixed with $\mathrm{NH}_{2}$-functionalized AuNP solution, resulting in the displacement of NHS groups of the activated lipase by the amino groups present on the AuNP surface and formation of covalent bond. In this way, a lipase monolayer was immobilized onto the surface of $\mathrm{NH}_{2}$ functionalized AuNPs through the covalent linkage, i.e., the AuNP- $\mathrm{NH}_{2}$-lipase nanozyme composite was obtained. With the knowledge of number of available Asp and Glu on the surface of lipase, it was easy to maintain the ratio of EDC and NHS with enzyme concentration. The activating agent has been used in such a way that limited conjugation can occur with maximum proper orientation. To know the particular concentration at which complete covering of nanoparticles four different concentrations of lipase (Table 1) were used for conjugation and $1 \mu \mathrm{mol} \mathrm{ml}{ }^{-1}$ was found to be the best for conjugation reaction. Although lowest concentration of lipase $\left(0.5 \mu \mathrm{mol} \mathrm{ml}{ }^{-1}\right)$ has also shown good immobilization efficiency but this conjugate solution is not stable for longer period and precipitate. Therefore, lipase conjugated at $1 \mu \mathrm{mol} \mathrm{ml} \mathrm{ml}^{-1}$ (in terms of protein content) concentration has been used for rest of the study.

Fig. 3A shows the UV-visible spectra of unconjugated AuNPs$\mathrm{NH}_{2}$ and conjugated AuNP- $\mathrm{NH}_{2}$-lipase, in which the peak indicates the characteristic surface plasmon resonance (SPR) of gold nanoparticles. Immobilization of lipase on the surface of AuNPs- $\mathrm{NH}_{2}$ leads to an increase in nanoparticles size, which results in the redshift of spectra $(<10 \mathrm{~nm})$. It is well known that larger size nanoparticles have an absorbance at a higher wavelength as compared to the smaller size nanoparticles of same shape and morphology. ${ }^{31}$ Thus, the redshift of the spectra indicated the presence of the enzyme on the AuNP- $\mathrm{NH}_{2}$ surface as observed by other groups (Fig. 4$).^{32}$

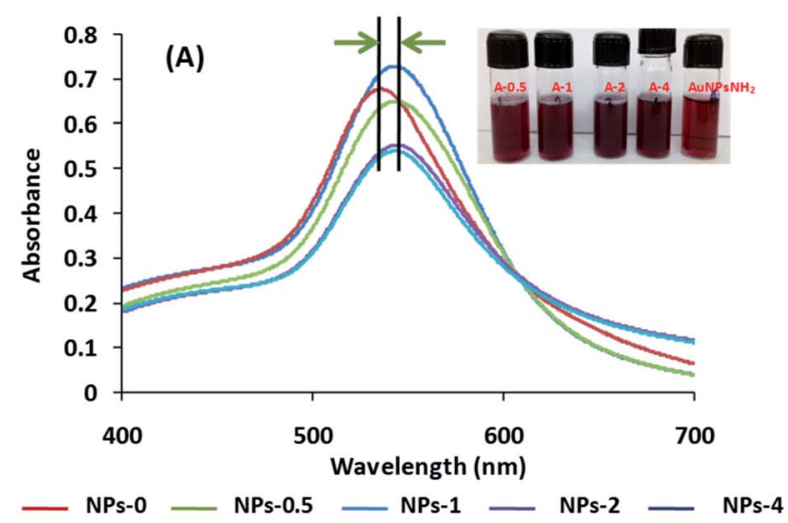

(B)
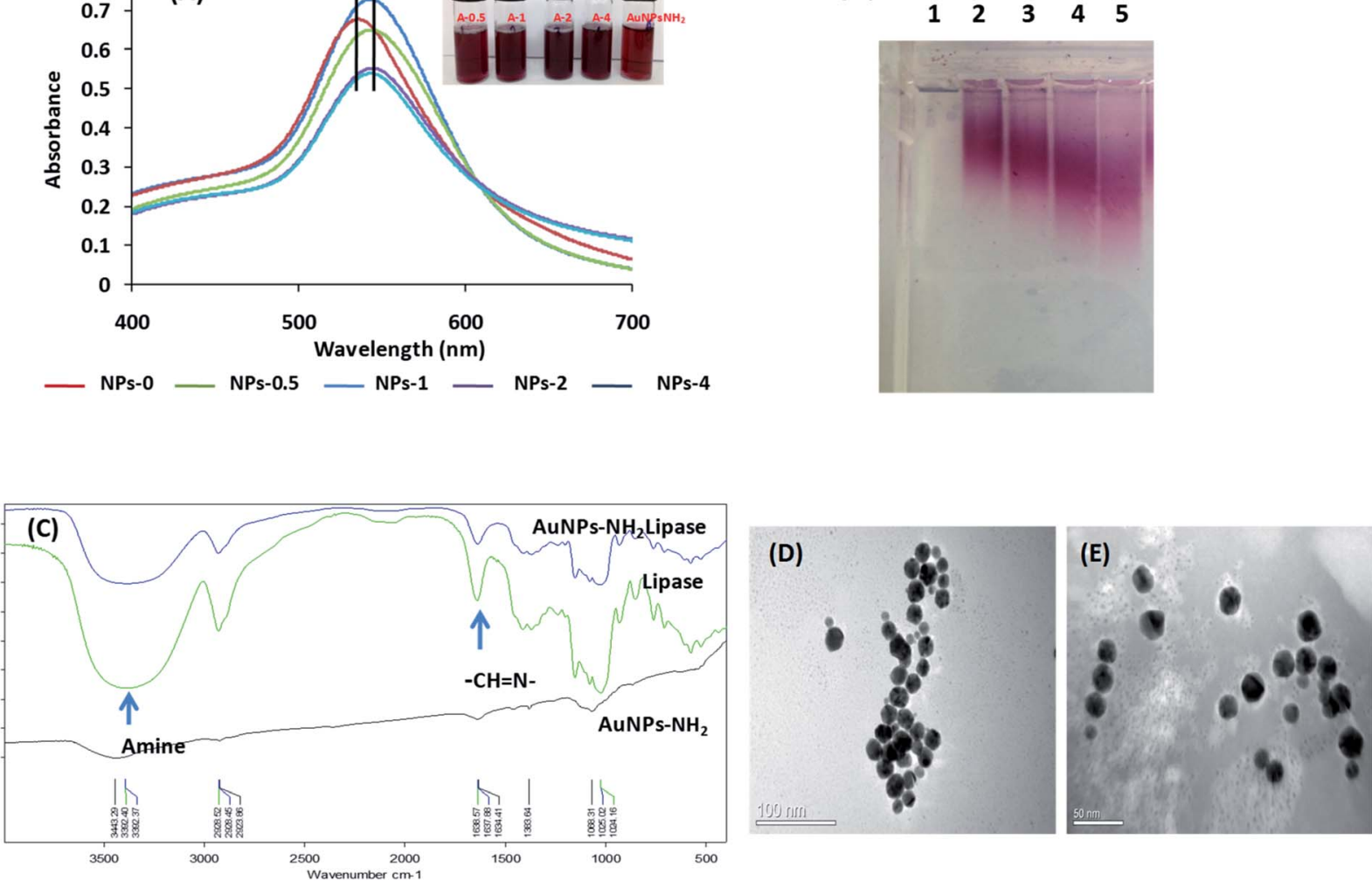

Fig. 3 UV-visible spectra of AuNPs- $\mathrm{NH}_{2}$ before conjugation (red colour spectra, represented as NPs-0) and after conjugation with different concentration of lipase $\left(0.5,1,2,4 \mu \mathrm{mol} \mathrm{ml} l^{-1}\right.$, represented as NPs with its concentration). Inset; AuNPs- $\mathrm{NH}_{2}$ with lipase conjugated (from left, first to forth sample) and without conjugation (right last) (A). Agarose gel electrophoresis of unconjugated and conjugated AuNPs- $\mathrm{NH}_{2}$ (B). Lane'1' represents unconjugated AuNPs- $\mathrm{NH}_{2}$ and remaining lanes 2, 3, 4 and 5 represent different concentration of lipase used for conjugation (0.5, 1, 2, $4 \mu \mathrm{mol} \mathrm{ml}{ }^{-1}$ ) respectively. FTIR spectra of AuNPs- $\mathrm{NH}_{2}$, lipase and AuNPs- $\mathrm{NH}_{2}$-lipase conjugate (C). TEM imaging of AuNPs-NH 2 (D) and AuNPs$\mathrm{NH}_{2}$-lipase conjugate (E). 
(A)

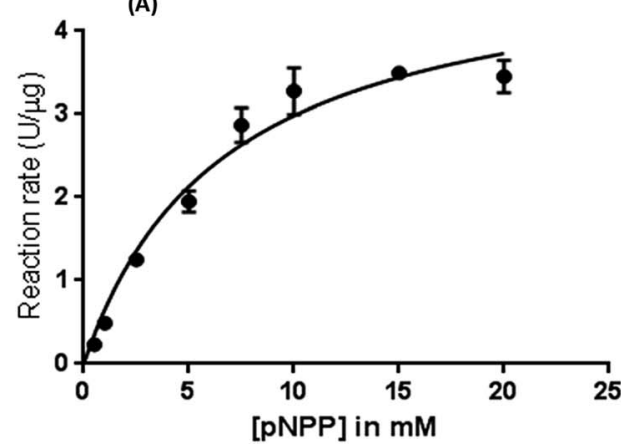

(B)

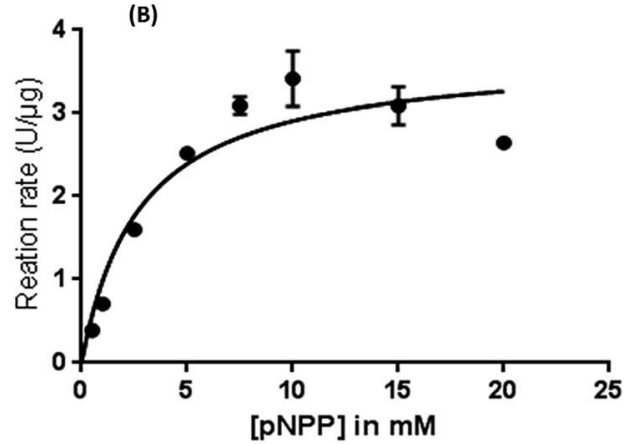

Fig. 4 Michaelis-Menten saturation curve for free lipase (A) and AuNPs-NH -lipase (B) reaction showing the relation between the $p$-nitrophenyl palmitate ( $p$-NPP) and reaction rate. The graph has been plotted using Prism 6 software.

Zeta potential ( $\zeta)$ is a measure of surface charges carried by the nanoparticles in a suspension. Zeta potential value of conjugated nanoparticles showed that it has a lower surface charge compared to the unconjugated gold nanoparticles (as shown in Table 1 and Fig. 3B). Similar finding was also observed by Silva et al., in which they have used PEG coated polystyrene nanoparticles for conjugation of lipase..$^{33}$ Lowering of zeta value indicates the masking of AuNPs- $\mathrm{NH}_{2}$ with lipase molecules that was also confirmed by gel electrophoresis ( $0.8 \%$ agarose). The gel shift increases with increasing concentration of protein supporting the decrease in $\zeta$ value, thus confirming the conjugation in all cases. Wangoo et al., also observed similar phenomenon using negatively charged nanoparticles. ${ }^{34}$ Immobilization efficiency (\%) determined by Bradford assay indicates that maximum immobilization had occurred at the concentration of $1 \mu \mathrm{mol} \mathrm{ml}{ }^{-1}$ of lipase. Therefore, this concentration was used for immobilization to carry rest of studies.

\section{FTIR}

Furthermore, the confirmation of immobilization of lipase to AuNPs-NH $\mathrm{N}_{2}$ was characterized by FTIR spectroscopy. As shown in Fig. 3C, in the case of unconjugated gold nanoparticles (AuNPs$\mathrm{NH}_{2}$ ), stretches at $1020-1250 \mathrm{~cm}^{-1}$ and at $3443 \mathrm{~cm}^{-1}$ affirms the presence of amines $\left(1^{\circ}\right.$, due to the presence of cysteamine- $\left.\mathrm{HCl}\right)$ that capped the gold nanoparticles. These peaks are further sharpening in AuNPs- $\mathrm{NH}_{2}$-lipase and have followed pattern as of free lipase. The characteristic bands of pure lipase were at 3392 (O-H stretching and $\mathrm{N}-\mathrm{H}$ stretching vibrations), 1638 (amide), and $1024 \mathrm{~cm}^{-1}$ (C-O-C stretching vibration), is consistent with the previous report. ${ }^{35}$ The AuNPs- $\mathrm{NH}_{2}$-lipase had the pattern of pure lipase, confirming the immobilization of lipase to nanoparticles. Therefore, the FTIR results provided the evidential information of modified AuNPs- $\mathrm{NH}_{2}$-lipase.

\section{TEM}

The morphological characterization of conjugated/ unconjugated AuNPs- $\mathrm{NH}_{2}$ was carried out by TEM. Fig. 3D shows the well-dispersed cysteamine stabilized AuNPs- $\mathrm{NH}_{2}$ with size of about $25 \pm 3 \mathrm{~nm}$ in diameter. As peripheral protein layer cannot be imaged due to the low electron resistance of protein molecules in TEM examination, therefore nanozyme composites were stained by $2 \%$ PTA. In Fig. 3E, the faint white layer around the periphery of conjugated gold nanoparticles was visualized that indicates the presence of biomolecules and thus demonstrating immobilization of lipase to amine functionalized gold nanoparticles. ${ }^{36}$

\section{Enzyme kinetics measurement}

The consequences of immobilization on the enzyme kinetics were studied by determining the activity of the native enzyme and AuNPs- $\mathrm{NH}_{2}$-lipase nanozyme composite using para-nitrophenolpalmitate ( $p$-NPP) as substrate. The apparent MichaelisMenten constant $\left(K_{\mathrm{M} \text {,app }}\right)$ of the free-lipase and AuNP- $\mathrm{NH}_{2}$-lipase was determined by plotting Michaelis-Menten saturation curve using Prism 6 software. The $K_{\mathrm{M} \text {,app }}$ of the immobilized lipase was decreased by 2.43 -fold over that of free lipase (Table 2). Since, $K_{\mathrm{M} \text {,app }}$ is related to the binding affinity of enzyme to the substrate, lowering of $K_{\mathrm{M} \text {,app }}$ of nanozyme composite indicates that the conjugation has led to the increase in substrate binding affinity. Similar findings were also observed by various groups when lipase has been conjugated to different supports. ${ }^{33,37-39}$ The $V_{\max }$ value for AuNPs- $\mathrm{NH}_{2}$-lipase was lower than that for free lipase. Conjugation leads to change not only in $K_{\mathrm{M} \text {,app }}$ but also in $V_{\max }$ that suggested the stabilized the transition state. Moreover, 1.8fold higher value of $V_{\max } / K_{\mathrm{M} \text {,app }}$ for AuNP- $\mathrm{NH}_{2}$-lipase conjugate over free lipase indicated that the conjugated lipase binds to the substrate more easily and have significantly higher catalytic efficiency. The catalytic efficiencies of different enzymes can be considered by evaluating the specificity constant $\left(K_{\text {cat }} / K_{\mathrm{M} \text {,app }}\right)$. It defines rate constant for the conversion of substrate to product

Table 2 Kinetic parameters of the free-lipase and AuNPs- $\mathrm{NH}_{2}$-lipase conjugate on $p$-nitrophenyl palmitate ( $p$-NPP)

\begin{tabular}{lrc}
\hline Parameter & Free lipase & AuNPs-NH ${ }_{2}$-lipase \\
\hline$V_{\max }\left(\mathrm{U}^{-1}\right)$ protein & 4.98 & 3.71 \\
$K_{\mathrm{m}, \text { app }}(\mathrm{mM})$ & 6.70 & 2.76 \\
$K_{\text {cat }}\left(\mathrm{s}^{-1}\right)$ & 2763.30 & 2059.05 \\
$K_{\text {cat }} / K_{\mathrm{M}, \text { app }}\left(\mathrm{s}^{-1} \mathrm{mM}^{-1}\right)$ & 412.38 & 744.95
\end{tabular}


and this has increased up to $80 \%$ as compared free lipase. The possible reasons of the enhanced activity of immobilized lipase are as follow: (i) maintenance of "open state" conformation of lipase due to immobilization; ${ }^{\mathbf{4 0}-42}$ (ii) prevention of aggregation of free lipase due to immobilization $;^{\mathbf{1 7}, 43}$ and (iii) change in enzyme conformation due to interfacial activation. ${ }^{\mathbf{4 1 , 4 4}}$ Either one or all might be possible for enhanced activity. It suggests that covalent binding of lipase to AuNPs- $\mathrm{NH}_{2}$ might have occurred at such sites that facilitated the easy accessibility of substrate to the catalytic sites by keeping its active conformation open, leading to significant increase in catalytic efficiency. ${ }^{\mathbf{4 , 4 1 , 4 5}}$

\section{Thermodynamic studies}

Subsequent to establishment of enhanced catalytic parameters of AuNP-NH $\mathrm{N}_{2}$-lipase nanozyme composite, the enzyme activity was measured in the temperature range of $20-80^{\circ} \mathrm{C}$ (an interval of 10 unit) to know temperature optima and thermodynamic stability. Free-lipase and AuNPs- $\mathrm{NH}_{2}$-lipase conjugate, both have shown maximum activity at $50{ }^{\circ} \mathrm{C}$ (assigning maximum value as $100 \%$, from which relative activity has been calculated for different temperatures). AuNPs- $\mathrm{NH}_{2}$-lipase retains $65 \%$ of its maximum activity at $60{ }^{\circ} \mathrm{C}$ whereas free lipase has nearly $20 \%$ (Fig. 5A). It is well known that higher temperature leads to denaturation of protein, resulting in loss of activity, but the AuNPs- $\mathrm{NH}_{2}$-lipase conjugate is resistance to the denaturation of protein. In case of conjugated AuNPs- $\mathrm{NH}_{2}$-lipase, nanoparticles act as a support that either minimize the denaturation process or act as a scaffold to speed up the renaturation of protein. ${ }^{46}$ Along with the maintenance of active open conformation as mentioned earlier, immobilization generally increases the rigidity of the protein and thus increases the thermal stability of the immobilized enzyme. ${ }^{46}$

Irreversible thermal deactivation can be best described by measuring the kinetic stability of the enzyme. Thermal deactivation of lipase has been found to follow the first order kinetics and can be described by the following expression:

$$
N_{\mathrm{L}} \stackrel{K_{\mathrm{D}}}{\longrightarrow} D_{\mathrm{L}}
$$

where, $N_{\mathrm{L}}$ represents the native enzyme, $D_{\mathrm{L}}$ represents the deactivated enzyme and $K_{\mathrm{D}}$ represents the between the native and the deactivated states, and can be related to the fraction of lipase present in the deactivated state $\left(f_{D_{\mathrm{L}}}\right)$,

$$
K_{\mathrm{D}}=\frac{f_{D_{\mathrm{L}}}}{f_{N_{\mathrm{L}}}}=\frac{f_{D_{\mathrm{L}}}}{1-f_{N_{\mathrm{L}}}}
$$

where, $f_{N_{\mathrm{L}}}$ represents the fraction of enzyme present in the native state and $f_{D_{\mathrm{L}}}$ represents the fraction of enzyme present in the deactivated state.

$f_{D_{\mathrm{L}}}$ may be calculated by

$$
f_{D_{L}}=\frac{A_{\mathrm{N}}-A}{A_{\mathrm{N}}-A_{\mathrm{D}}}
$$
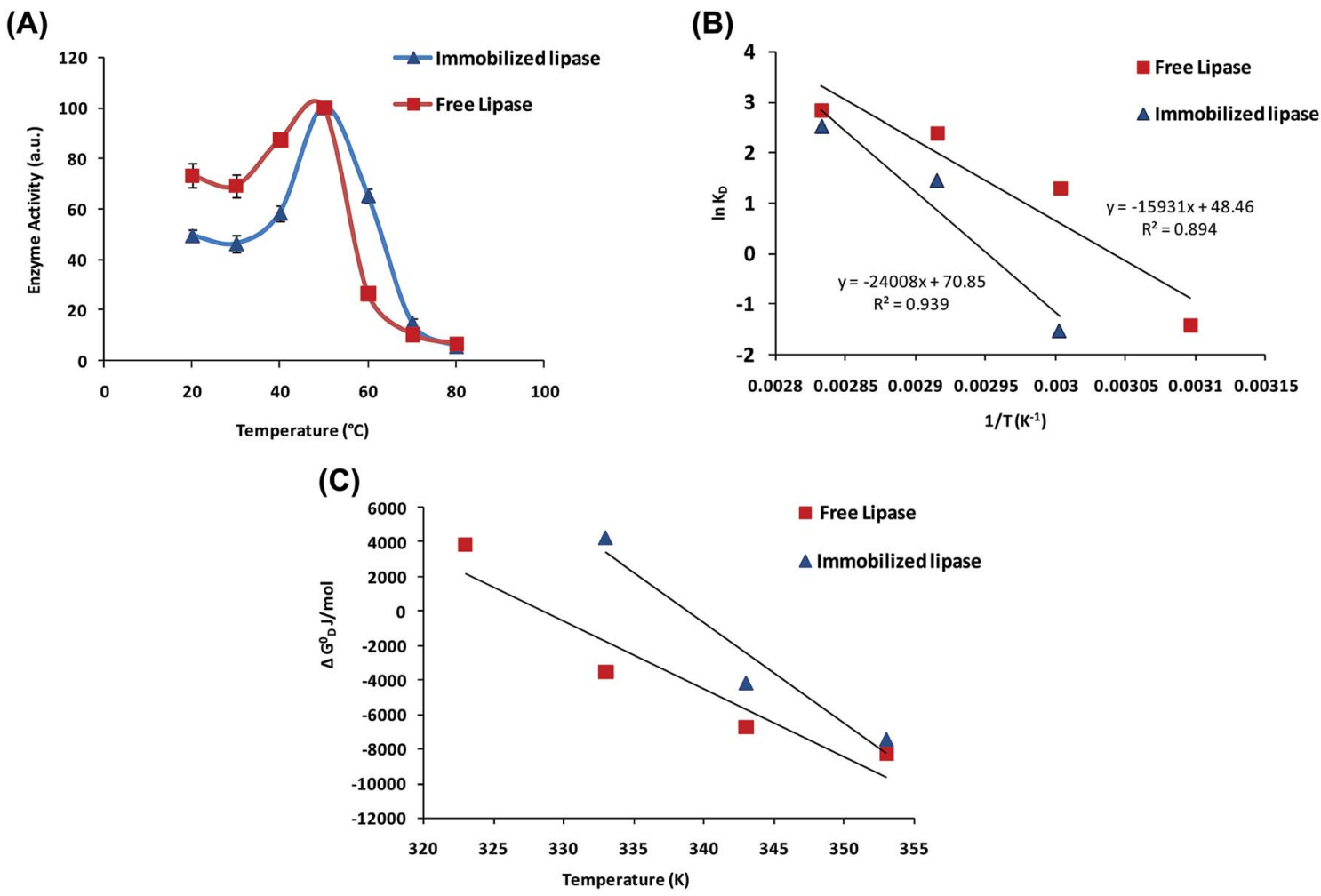

Fig. 5 Relative activity of free lipase and immobilized lipase (AuNPs-NH - -lipase) as a function of temperature (A). Van't Hoff plot for free lipase and immobilized lipase conjugate with differing temperature sensitivities (B). Gibbs free energy of deactivation ( $\left.\Delta G_{\mathrm{D}}^{\circ}\right)$ as a function of temperature: free lipase and immobilized lipase conjugate (C). The temperature was increased gradually from $40-80{ }^{\circ} \mathrm{C}$ and samples were incubated for an hour. 
where, $A$ is the observed activity of the enzyme at a given temperature and $A_{\mathrm{N}}$ and $A_{\mathrm{D}}$ the activities at native and deactivated conditions, respectively.

The equilibrium constant $K_{\mathrm{D}}$ is related to Gibbs free energy for deactivation

$$
\Delta G_{\mathrm{D}}^{\circ}=-R T \ln K_{\mathrm{D}}
$$

where, $R$ and $T$ gas constant and temperature respectively.

Thermodynamic parameters, i.e., standard state enthalpy $\left(\Delta H_{\mathrm{D}}^{\circ}\right)$ and standard state entropy $\left(\Delta S_{\mathrm{D}}^{\circ}\right)$ of enzyme deactivation have been calculated from Van't Hoff plot (Fig. 5B, Table 3). For this, data were selected from the range of 50 to $80{ }^{\circ} \mathrm{C}$ and compared. It was found that, the $\Delta H_{\mathrm{D}}^{\circ}$ value of nanozyme composite $\left(-199.60 \mathrm{~kJ} \mathrm{~mol}^{-1}\right)$ is higher than free enzyme $\left(-132.45 \mathrm{~kJ} \mathrm{~mol}^{-1}\right)$ indicating that the nanozyme composite is more thermostable than free enzyme. On the other hand, the entropic values of the free enzyme (402.84 $\left.\mathrm{J} \mathrm{mol}^{-1} \mathrm{~K}^{-1}\right)$ and nanozyme composite $\left(589.04 \mathrm{~J} \mathrm{~mol}^{-1} \mathrm{~K}^{-1}\right)$ indicated that the enzyme is more thermostable. However, the free energy of deactivation $\left(\Delta G_{\mathrm{D}}^{\circ}\right)$ includes both the enthalpic and entropic contribution and is more accurate and reliable parameter for the prediction of enzyme stability. Therefore, the $\Delta G_{\mathrm{D}}^{\circ}$ of the two enzymes was derived from eqn (1d) and plotted against the temperature and it was found that, the $\Delta G_{\mathrm{D}}^{\circ}$ value of the nanozyme was higher than the free enzyme (Fig. $5 \mathrm{C}$ ). A higher $\Delta G_{\mathrm{D}}^{\circ}$ is associated with higher tolerance towards temperature deactivation, supporting the enzyme active conformation and thus confirms higher thermostability of AuNPs- $\mathrm{NH}_{2}$-lipase nanozyme conjugates as compared to free enzyme. From the same graph, when transition midpoint temperature $\left(T_{\mathrm{m}}\right.$; Table 3$)$ of these two enzymes were compared, it was found that AuNPs- $\mathrm{NH}_{2}$-lipase nanozyme composite has higher $T_{\mathrm{m}}$ by unit of $10{ }^{\circ} \mathrm{C}$. These results clearly show that the conjugation enhances the thermostability of enzyme consistent with previous finding obtained by Prashant et al., ${ }^{\mathbf{4}}$

\section{Time dependent thermal stability study}

Further, a time course comparison of activity was performed at 40, 50 and $60{ }^{\circ} \mathrm{C}$ for free and conjugated lipase. Fig. 6 clearly demonstrates that over an hour, the AuNP- $\mathrm{NH}_{2}$-lipase nanozyme composite has $110 \%$ and $130 \%$ higher activity at $40{ }^{\circ} \mathrm{C}$ and $50{ }^{\circ} \mathrm{C}$ respectively as compared to the free lipase. In the similar condition, free lipase was able to retain only $70 \%$ and $67 \%$ of its native enzyme activity. The conjugated nanoparticles retained its nearly $80 \%$ of activity at $50{ }^{\circ} \mathrm{C}$ even after 4 hour of incubation whereas the free enzyme has nearly $30 \%$. A very interesting finding that the nanozyme composite is able to retain its activity more than $50 \%$ after incubating at $60{ }^{\circ} \mathrm{C}$ for an hour whereas the

Table 3 Thermodynamic parameter of lipase and AuNPs- $\mathrm{NH}_{2}$-lipase conjugate

\begin{tabular}{|c|c|c|c|}
\hline Parameter & $\Delta H_{\mathrm{D}}^{\circ}\left(\mathrm{kJ} \mathrm{mol}^{-1}\right)$ & $\Delta S_{\mathrm{D}}^{\circ}\left(\mathrm{J} \mathrm{mol}^{-1} \mathrm{~K}^{-1}\right)$ & $T_{\mathrm{m}}(\mathrm{K})$ \\
\hline Free lipase & 132.45 & 402.89 & 328.75 \\
\hline AuNPs-NH ${ }_{2}$-lipase & 199.60 & 589.04 & 338.86 \\
\hline
\end{tabular}

free enzyme loses nearly all of its activity. Denaturation of enzyme (a protein) is temperature dependent and if the protein is denatured to an extent from which there is no recovery of active conformational structure that leads to activity loss. Here, fall in activity of free enzyme at all temperature suggested loss of active conformation after denaturation with respect to time. Contrary to this, immobilized lipase have shown the activity (at $40{ }^{\circ} \mathrm{C}$ and $50^{\circ}$ ) initially gain and then retain its activity (upto 80\%) for longer time period. The gain of thermostability can be attributed towards covalent multipoint immobilization due to zero length crosslinker. This multipoint attachment have contributed towards structural rigidity, stability of secondary structure and active conformation of lipase, that prevents from denaturation of immobilized enzyme at higher temperature. ${ }^{4,48}$ This reinforced that immobilization of lipase on amine gold nanoparticles enhances the thermostability of enzyme that can be potentially useful for industrial applications. ${ }^{49}$

\section{pH and storage stability study}

For pH stability analysis, free and immobilized enzyme were kept in buffers of different pHs ranging from 4-10 for an hour at RT and the activity was analyzed at $37^{\circ} \mathrm{C}$. It was observed (ESI Fig. $1 \mathrm{~A} \dagger)$ that at lower $\mathrm{pH}(4-6)$, the activity of AuNPs- $\mathrm{NH}_{2}$-lipase is less than free enzyme that is reversed at higher $\mathrm{pH}(7-10)$. Lowering of $\mathrm{pH}$ might have disturbed the integrity of gold nanoparticles, ultimately affected the enzyme activity.

AuNPs- $\mathrm{NH}_{2}$-lipase nanozyme composite can be stored for a month, and its activity was determined at an interval of 5 days. ESI Fig. $1 \mathrm{~B} \dagger$ clearly indicates that AuNPs- $\mathrm{NH}_{2}$-lipase can retain $60 \%$ of its activity after 25 days whereas enzyme solution lost most of its activity within 20 days of storage similar to previous finding. ${ }^{50}$ The possible reason for this stability is inhibition of aggregation of enzyme in solution whereas maintenance of open conformation of the enzyme. ${ }^{7}$ In this way, it can be said that AuNPs- $\mathrm{NH}_{2}$ facilitates durable attachment that provides the structure and long-term stability of immobilized lipase.

In order to know the stability of nanoparticles before and after conjugation, samples were withdrawn periodically at an interval of 5 days and UV spectrum was measured. It is already shown earlier that the conjugated nanoparticles have red shift in UV spectra as compared to unconjugated nanoparticles. After 5 days incubation, the SPR of the unconjugated nanoparticles (shown in ESI Fig. 2A $\dagger$ ) have shown broadening of peak indicating the increase in size of nanoparticles. Disappearance of SPR peak at $530 \mathrm{~nm}$ and appearance of band after $600 \mathrm{~nm}$ indicated the increase in aggregation of the nanoparticles and the settlement of nanoparticles at the bottom of tube was also seen by naked eyes. However there is negligible change in UVspectra of conjugated nanoparticles (shown in ESI Fig. 2B $\dagger$ ) with time at different time scale suggesting no aggregation and confirming its stability. The stability of nanoparticles can be explained by Derjaguin-Landau-Verwey-Overbeek (DLVO) theory $^{51}$ in which the colloidal particles are stabilized by two major forces; long range electrostatic repulsion and short range van der Waals attraction. Here it is shown in Table 1 that unconjugated nanoparticles have very high zeta potential as 


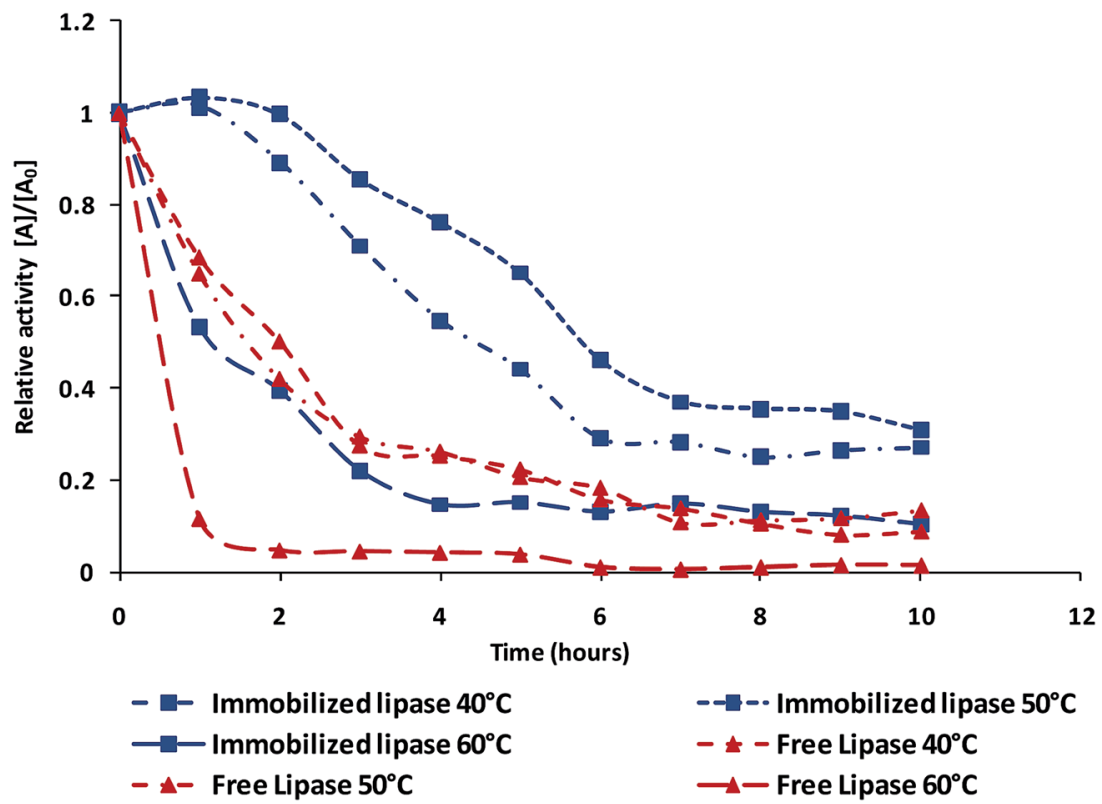

Fig. 6 Relative activity free lipase and immobilized lipase conjugate as a function of time at three different temperatures $\left(40,50\right.$ and $\left.60{ }^{\circ} \mathrm{C}\right)$.

compared to conjugated nanoparticles, the electrostatic repulsion forces dominate over van der Waals attraction forces that led to aggregation.

\section{Structural characterization of AuNPs- $\mathrm{NH}_{2}$-lipase}

\section{CD analysis}

The retention of enzyme activity is the primary concern while performing immobilization especially covalent immobilization. The activity of protein mainly depends on its structural integrity (3D conformation). ${ }^{52}$ Various interactions as an outcome of conjugation may influence the structural integrity and thereby affect the activity of the enzyme (in the present enhanced activity and stability). Therefore, it was necessary to understand the structural changes occurred in the enzyme molecule due to immobilization. Thus, we conducted $\mathrm{CD}$ and fluorescence spectroscopic studies on both the free and AuNPs- $\mathrm{NH}_{2}$-lipase conjugates. The secondary structure profile of lipase is shown in Fig. 7A. Lipase is $\alpha$-helical protein. CD spectrum of lipase shows negative peaks at 222 and $208 \mathrm{~nm}$, characteristic of $\alpha$-helical proteins (Fig. 7A). While the peak at $222 \mathrm{~nm}$ is comparable, peak at $208 \mathrm{~nm}$ is shifted by $3-4 \mathrm{~nm}$ for conjugated lipase indicating some structural rearrangements. The content of $\alpha$-helix and $\beta$ sheet were calculated from K2D3 analysis server (http://cbdm01.zdv.uni-mainz.de/ andrade/cgi-bin/k2d3/k2d3_set1.pl). The $\alpha$-helix and $\beta$-sheet content of free lipase were $77.44 \%$ and $1.37 \%$ whereas for AuNPs-lipase have $\mathbf{7 7 . 1 7 \%}$ and $1.57 \%$ respectively. It indicates that, while there were minor secondary structural changes in the lipase due to conjugation with AuNPs- $\mathrm{NH}_{2}$ coincidentally, there was a desirable increase in the activity and stability. Here, the partial structural loss of immobilized lipase can be correlated to the involvement of surface carboxyl group of enzyme in covalent linkage that lead to alteration of hydrogen bond among functional groups to some extent and leading to smaller change in enzyme structure. ${ }^{53,54}$

\section{Fluorescence analysis}

To support CD experiments, fluorescence measurements were performed to investigate the effect of AuNPs on tertiary structure of lipase. Lipase has three intrinsic fluorophores: tryptophan,
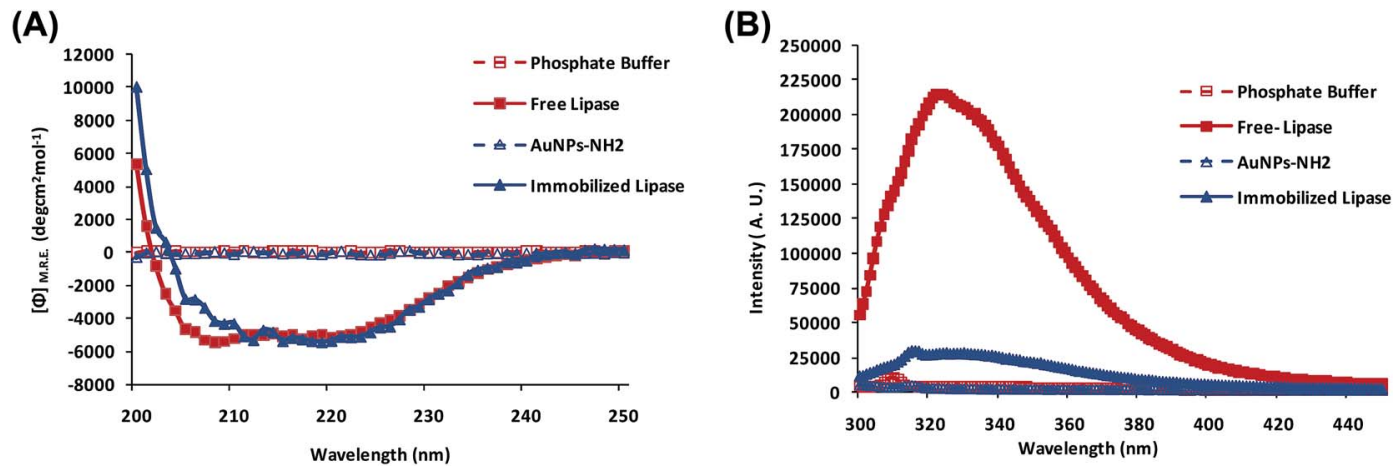

Fig. 7 CD spectra (A) and fluorescence intensity (B) of free lipase and immobilized lipase. 
tyrosine and phenylalanine that can be quenched, in which the main intrinsic fluorophore is tryptophan. The fluorescence emission maximum of tryptophan (Trp) is affected by $\mathrm{pH}$ of the solution and microenvironment of the particular residues. The lipase displays a fluorescence emission spectrum with a peak at $323 \mathrm{~nm}$ (Fig. 7B) under our experimental conditions. ${ }^{55}$ Fig. 7B shows that there is significant (nearly nine times) decrease in emission intensity of AuNP- $\mathrm{NH}_{2}$-lipase conjugate as compared to the free enzyme. Iosin et al., has shown relationship of fluorescence intensity between shape and size of gold nanoparticles to the concentration of protein. ${ }^{56}$ In which they have demonstrated that the complete binding of nanoparticles to enzyme leads to nearly complete quenching of fluorescence. Apart from this strong quenching effect, a redshift of about $2 \mathrm{~nm}$ (323 to $325 \mathrm{~nm}$ ) in the fluorescence peak was also observed indicating some microenvironmental change near the Trp residues. Thus, fluorescence studies confirm the structural integrity of lipase before and after immobilization and its relation with enhanced stability.

The stability of immobilized enzyme depends on various factors; nature of nanoparticles, interaction between enzyme and carrier, linking agents, binding positions of enzyme, number of bonds, properties of spacer, microenvironment of enzyme-conjugate and condition under which immobilization is performed whereas in case of native enzymes, its only intrinsic structure of protein affects the stability. Interestingly in our study, immobilization of lipase to amine functionalized gold nanoparticles contributed in gain of kinetic, thermo stability and storage stability as compared to free enzyme and that has been correlated well with structural studies. Thus, it can be said that the significance of study lie in the fact that the information obtained through structural studies helped in proceeding conjugation reaction and obtaining such immobilized lipase having minimum loss of structure with higher in various stability parameters.

\section{Conclusion}

Though, previously lipases have been conjugated with nanoparticles using different methods, but these methods involves multiple steps such as modification of nanoparticles surface to obtain desired functional group or modification of enzyme that can also alter its structure. Here, we have used cost effective method, and achieved maximum loading of lipase to nanoparticles. The elegance of this method lies mainly on; (i) obtaining amine functionalized gold nanoparticle in one step, (ii) the involvement of single step EDC/NHS chemistry for covalent conjugation and on the exploitation surface exposed acidic amino acids of the enzyme for immobilization to AuNPs$\mathrm{NH}_{2}$. The immobilization was achieved with advantages of higher kinetic and thermal stability but, minimum alteration of the structure and this has been correlated with CD and fluorescence measurements. This study also revealed that there is little change in the secondary structural of protein and that has provided enhanced thermal and storage stability. Therefore, it can be concluded that covalent conjugation in this way is reliable in obtaining nanozyme composite having enhanced activity, stability with the minor secondary changes. Such nanozyme composite formulations will be useful for various applications in industries due to their above mentioned qualities.

\section{Author contributions}

S. S. and M. S. B. designed the study. S. S. performed all the experiments, collected data. S. S. and M. S. B. analyzed results and drafted the manuscript. K. G. T. helped in analysis and interpretation of lipase structure.

\section{Conflicts of interest}

The authors declare that they have no competing interest.

\section{Acknowledgements}

Sristy Shikha is thankful to ICMR, New Delhi, India, for the research fellowship. The authors also thankfully acknowledge the help of Mr Shashi and Mr Randeep for obtaining the FTIR spectra and TEM images of the samples. The authors thankfully acknowledge CSIR-India for proving funds to carry out research under project no. OLP-0082.

\section{References}

1 R. Singh, M. Kumar, A. Mittal, P. K. Mehta, 3 Biotech, 2016, vol. 6.

2 M. Vellard, Curr. Opin. Biotechnol., 2003, 14, 444-450.

3 W. Tischer and F. Wedekind, Top. Curr. Chem., 1999, 200, 95-126.

4 C. Mateo, J. M. Palomo, G. Fernandez-Lorente, J. M. Guisan and R. Fernandez-Lafuente, Enzyme Microb. Technol., 2007, 40, 1451-1463.

5 U. Hanefeld, L. Gardossi and E. Magner, Chem. Soc. Rev., 2009, 38, 453-468.

6 G. A. Petkova, K. Zaruba, P. Zvatora and V. Kral, Nanoscale Res. Lett., 2012, 7, 287.

7 D. Bartczak and A. G. Kanaras, Langmuir, 2011, 27, 1011910123.

8 H. Shen, A. M. Jawaid and P. T. Snee, ACS Nano, 2009, 3, 915923.

9 S. Ding, A. A. Cargill, I. L. Medintz and J. C. Claussen, Curr. Opin. Biotechnol., 2015, 34, 242-250.

10 J. Kim, J. W. Grate and P. Wang, Chem. Eng. Sci., 2006, 61, 1017-1026.

11 P. M. Tiwari, K. Vig, V. A. Dennis and S. R. Singh, Nanomaterials, 2011, 1, 31-63.

12 M. Hu, L. Qian, R. P. Brinas, E. S. Lymar, L. Kuznetsova and J. F. Hainfeld, J. Struct. Biol., 2008, 161, 83-91.

13 Y. Y. Li, H. J. Schluesener and S. Q. Xu, Gold Bull., 2010, 43, 29-41.

14 K. E. Jaeger and M. T. Reetz, Trends Biotechnol., 1998, 16, 396-403.

15 R. Sharma, Y. Chisti and U. C. Banerjee, Biotechnol. Adv., 2001, 19, 627-662. 
16 F. Hasan, A. A. Shah and A. Hameed, Enzyme Microb. Technol., 2006, 39, 235-251.

17 Y. Ren, J. G. Rivera, L. He, H. Kulkarni, D. K. Lee and P. B. Messersmith, BMC Biotechnol., 2011, 11, 63.

18 J. Wang, G. Meng, K. Tao, M. Feng, X. Zhao, Z. Li, H. Xu, D. Xia and J. R. Lu, PLoS One, 2012, 7, e43478.

19 Y. Wu, Y. Wang, G. Luo and Y. Dai, Bioresour. Technol., 2009, 100, 3459-3464.

20 T. Fischer and H. Hess, J. Mater. Chem., 2007, 17, 943-951.

21 S. H. Lee, K. H. Bae, S. H. Kim, K. R. Lee and T. G. Park, Int. J. Pharm., 2008, 364, 94-101.

22 M. J. Fischer, Methods Mol. Biol., 2010, 627, 55-73.

23 M. M. Bradford, Anal. Biochem., 1976, 72, 248-254.

24 N. Gupta, P. Rathi and R. Gupta, Anal. Biochem., 2002, 311, 98-99.

25 C. H. Kuo, Y. C. Liu, C. M. J. Chang, J. H. Chen, C. Chang and C. J. Shieh, Carbohydr. Polym., 2012, 87, 2538-2545.

26 X. W. Cao, J. K. Yang, L. Shu, B. Q. Yu and Y. J. Yan, Process Biochem., 2009, 44, 177-182.

27 P. Rathi, R. K. Saxena and R. Gupta, Process Biochem., 2001, 37, 187-192.

28 F. Sasso, A. Natalello, S. Castoldi, M. Lotti, C. Santambrogio and R. Grandori, Biotechnol. J., 2016, 11, 954-960.

29 P. R. Mello Bueno, T. F. de Oliveira, G. L. Castiglioni, M. S. Soares Junior and C. J. Ulhoa, Water Sci. Technol., 2015, 71, 957-964.

30 J. D. Schrag, Y. G. Li, M. Cygler, D. M. Lang, T. Burgdorf, H. J. Hecht, R. Schmid, D. Schomburg, T. J. Rydel, J. D. Oliver, L. C. Strickland, C. M. Dunaway, S. B. Larson, J. Day and A. McPherson, Structure, 1997, 5, 187-202.

31 G. Raschke, S. Kowarik, T. Franzl, C. Sonnichsen, T. A. Klar, J. Feldmann, A. Nichtl and K. Kurzinger, Nano Lett., 2003, 3, 935-938.

32 S. K. Pandey, C. R. Suri, M. Chaudhry, R. P. Tiwari and P. Rishi, Mol. BioSyst., 2012, 8, 1853-1860.

33 R. A. Silva, A. M. Carmona-Ribeiro and D. F. S. Petri, Molecules, 2014, 19, 8610-8628.

34 N. Wangoo, K. K. Bhasin, S. K. Mehta and C. R. Suri, J. Colloid Interface Sci., 2008, 323, 247-254.

35 L. Z. Gao, J. M. Wu, S. Lyle, K. Zehr, L. L. Cao and D. Gao, J. Phys. Chem. C, 2008, 112, 17357-17361.
36 S. K. Pandey, C. R. Suri, M. Chaudhry, R. P. Tiwari and P. Rishi, Mol. BioSyst., 2012, 8, 1853-1860.

37 S. L. Cao, Y. M. Huang, X. H. Li, P. Xu, H. Wu, N. Li, W. Y. Lou and M. H. Zong, Sci. Rep., 2016, 6, 20420.

38 K. C. Badgujar and B. M. Bhanage, J. Phys. Chem. B, 2014, 118, 14808-14819.

39 A. K. Singh and M. Mukhopadhyay, Korean J. Chem. Eng., 2014, 31, 1225-1232.

40 M. T. Reetz, Adv. Mater., 1997, 9, 943-954.

41 P. Adlercreutz, Chem. Soc. Rev., 2013, 42, 6406-6436.

42 M. Mathesh, B. Q. Luan, T. O. Akanbi, J. K. Weber, J. Q. Liu, C. J. Barrow, R. H. Zhou and W. R. Yang, ACS Catal., 2016, 6, 4760-4768.

43 V. Sereti, M. Zoumpanioti, V. Papadimitriou, S. Pispas and A. Xenakis, J. Phys. Chem. B, 2014, 118, 9808-9816.

44 K. C. Badgujar, K. P. Dhake and B. M. Bhanage, Process Biochem., 2013, 48, 1335-1347.

45 P. Jochems, Y. Satyawali, L. Diels and W. Dejonghe, Green Chem., 2011, 13, 1609-1623.

46 Y. Xie, J. An, G. Yang, G. Wu, Y. Zhang, L. Cui and Y. Feng, J. Biol. Chem., 2014, 289, 7994-8006.

47 P. Asuri, S. S. Bale, R. C. Pangule, D. A. Shah, R. S. Kane and J. S. Dordick, Langmuir, 2007, 23, 12318-12321.

48 K. A. Mahmoud, E. Lam, S. Hrapovic and J. H. Luong, ACS Appl. Mater. Interfaces, 2013, 5, 4978-4985.

49 G. M. Zanin and F. F. De Moraes, Appl. Biochem. Biotechnol., 1998, 70-72, 383-394.

50 D. Andriani, C. Sunwoo, H. W. Ryu, B. Prasetya and D. H. Park, Bioprocess Biosyst. Eng., 2012, 35, 29-33.

51 N. J. Wagner and W. B. Russel, Phys. A, 1989, 155, 475-518.

52 S. M. Kelly and N. C. Price, Curr. Protein Pept. Sci., 2000, 1, 349-384.

53 F. Secundo, Chem. Soc. Rev., 2013, 42, 6250-6261.

54 P. Esmaeilnejad-Ahranjani, M. Kazemeini, G. Singh and A. Arpanaei, Langmuir, 2016, 32, 3242-3252.

55 Q. R. Jin, G. Q. Jia, Y. M. Zhang, Q. H. Yang and C. Li, Langmuir, 2011, 27, 12016-12024.

56 M. Iosin, F. Toderas, P. L. Baldeck and S. Astilean, J. Mol. Struct., 2009, 924, 196-200. 